\title{
Contra os limites da linguagem, a ética da imagem
}

\author{
Against the limits of language, \\ the ethics of the image
}

Peter Pelbart

Pontifícia Universidade Católica de São Paulo (PUC-SP)

Orcid 0000-0003-1880-0113

pppelbart@gmail.com

Resumo: Como nos autistas com quem trabalhou por muitos anos, para Fernand Deligny a imagem se contrapõe à linguagem pois recusa aquilo que esta carrega: sentido, mensagem, finalidade, palavras de ordem. Na sua teorização sobre o estatuto da imagem, Deligny dá a essa recusa uma dimensão ética e política.

Palavras-chave: Deligny; Imagem; Linguagem; Autismo.

Abstract: As for the autistic people he worked with for many years, for Fernand Deligny, image is opposed to language because the former refuses what the latter carries: meaning, message, purpose, slogans. In his theory about the status of the image, Deligny gives this refusal an ethical and political dimension.

Keywords: Deligny, image, language, autism. 
Frequentador de cinema desde a infância, hipnotizado pela clandestinidade da sala escura, Fernand Deligny sempre teve por esta arte um fascínio ambíguo. Pois não é propriamente o filme que o interessava, mas as imagens. Não a narratividade, o conteúdo, o sentido, a moral da história, para o dizermos brutalmente, mas aquilo que escapa ao domínio da linguagem ou à prevalência da história. Deligny se refere às imagens como gansos. Há aqueles, selvagens, que levantam vôo, seja frente a uma ameaça, seja na iminência do acasalamento, em todo caso em circunstâncias que têm a ver com a sobrevivência da espécie. Em contrapartida, há aqueles que, domesticados, apenas guardam dessa capacidade um tímido movimento de asas, sempre abortado. Não conseguem mais levantar vôo. Do mesmo modo as imagens: algumas levantam vôo, liberadas do que a linguagem nelas deposita, sejam mensagens ou conteúdos, e outras, domesticadas, civilizadas, por demais contaminadas pelos sentidos que carregam, pelos significados que veiculam, pelas mensagens de que são portadoras, pela linguagem com a qual estão associadas: estas mal esboçam um movimento próprio. Estão doentes, de tão incumbidas de transmitir o que quer que seja que não lhes pertence e que lhes é alheio (DELIGNY, 2007, p 1667). O que elas perdem, com isso, é justamente o "movimento" que está em sua origem. Eis o que importa, o movimento em sobressalto, o movimento sem finalidade que o autor chamava "agir" (contrariamente ao "fazer", que visa um objetivo). Dessas imagens "livres" tem-se uma memória outra, primeva. "Somos assediados por um povo de imagens", diz ele. Somos povoados por elas, mas elas não aparecem, por demais submersas pelas imagens domesticadas. Não é difícil domesticar um ganso, ou uma imagem. Apesar disso, gansos selvagens continuam levantando vôo e atravessando os céus em formação geométrica, em V. "As verdadeiras imagens, aquelas que não estão sobrecarregadas de representar o que quer que seja, têm, entre si, formas que só esperam as circunstâncias oportunas para desdobrarem-se como antes"(DELIGNY. 2007, p. 1671). Uma das questões do cinema é criar tais circunstâncias oportunas.

Mas seria preciso perguntar-se, antes disso: de onde viriam tais imagens? Primeira hipótese a afastar: elas não vêm 
da imaginação. Donde essa afirmação lapidar: as imagens não se imaginam. Claro, há as imagens imaginadas, inclusive pelo cineasta - estas são as domesticadas. Mas as imagens propriamente ditas não se imaginam, elas estão, são, existem, e não se vêem. Ou seja, não são feitas para serem vistas, não pressupõem uma alteridade, ou um sujeito, sequer o próprio sujeito que as carrega. As imagens "tout court", como diz Deligny, existem sem o eu, sem o sujeito, sem intenção alguma, fora de toda linguagem. Se os humanos habitam a linguagem, e pensam através dela, e com o cortejo de sentidos, intenções, encadeamentos, finalidade que ela carrega, há certamente um outro modo de pensar, preservado entre os autistas, e que se dá através de imagens. Tais imagens não se referem a um Si, não compõem uma reflexão. No reino de tais imagens, há ninguém.

Eis pois uma imagem que não representa, não reproduz, não intenciona, não significa, não pertence a ninguém, e que só pode surgir no improviso, ou imprevistamente, mesmo que para tanto seja necessária uma longa e elaborada preparação cinematográfica. Tais imagens talvez apareçam apenas "no meio", "por acaso", assim como a grama entre as plantas ou nas margens das estradas, como um "resto". São imagens que não pedem nada a ninguém. "A imagem existe e não quer dizer nada"!(DELIGNY, 2007, p.1690), ela está por toda parte e não se vê, porém persiste. Mas paradoxalmente, é também aquela que foge, e que escapa sobretudo ao que Deligny chama de "preneur d'images", aquele que "toma" imagens, ou as "capta", e que chamamos de cineasta. Mas como pode ser a imagem a alma do cinema, se justamente esta imagem "verdadeira" é aquela que foge, escapa, não comporta intenção, não faz história?

Daí a recusa em usar o verbo filmar. Costumamos designar certas ações a partir do instrumento que utilizamos (martelar, martelo), e não pelo resultado obtido (prego na parede). Por isso, quando elaboramos um livro, não dizemos livrar, porém escrever. Por que então designamos a operação cinematográfica pelo resultado em que ela desemboca, e não pelo processo de que depende? Talvez pudéssemos dizer "camerar", ao invés de filmar, pois ao usarmos a câmera poderíamos fazê-lo sem neces- 
sariamente visar um resultado, mais atentos ao processo do que à finalidade. Deligny gostaria de pensar a tomada de imagens de forma tal que elas não se submetessem a tal ou qual objetivo, projeto, história, finalidade. Portanto, reencontrar a imagem quase que à revelia da história do cinema que a curvou aos seus desígnios. Contra o filmar, o "camerar". Dispensável dizer que no camerar se ejeta precisamente aquilo que está no centro do filmar: o diretor, ou seu projeto, sua intenção, a obra final, o sentido. No fundo, a imagem é justamente aquilo que costuma "fazer falta" em um filme, a imagem é o que falta a nós. Com isso, talvez Deligny sonhe com uma arte em que não se quisesse, não se desejasse, não se visasse nada... Captar algo sob o signo do inquerer... Embora esteja por toda parte, a imagem é como o átomo, não se vê... Se camerar sai em busca da imagem, não significa que se vá encontrá-la, encoberta que está há tanto tempo pelas imagens domesticadas, cultas, legitimadas, cuja função, aliás, consiste entre outras coisas em abolir as imagens "verdadeiras". Não se trata, através do camerar, de reencontrar algum objeto perdido, porém um movimento persistente.

Deligny escreveu um livro, talvez na contramão de Heidegger, intitulado Acheminement vers l'image (o de Heidegger chamava-se em francês Acheminement vers la parole). Mas ele confessa que deveria chamar-se Acheminement vers l'imager. "Imagear" é o contrário de imaginar... Imaginar é antecipar as imagens. Imagear, em contrapartida, é como atrair os gansos selvagens, "imagens perdidas como o são todos esses infinitivos que escaparam à domesticação" (DELIGNY, 2007, p. 1731). Talvez, no fundo, e esta seria a hipótese radical de Deligny, a imagem seja "do reino animal" (DELIGNY, 2007, p. 1772), em outras palavras, provém da memória da espécie humana, e tem algo em comum com todas as demais espécies. Não se trata de fazer disso uma hipótese científica, "colossal", como seria a freudiana, pois no fundo não importa se é verdadeiro ou falso, importa que isso ajude a desfazer certos hábitos do "imaginar" ou "captar imagens" no modo de filmar. "A imagem no sentido em que eu a entendo, a própria imagem, é autista. Quero dizer que ela não fala. Uma imagem não diz nada, e, como no caso das crianças autistas, eis uma razão a mais para que todos a 
obriguem a dizer não sei o quê. A imagem aguenta firme." A imagem aguenta firme, isto é, ela resiste a significar aquilo que desejam lhe impor. E nisso há algo da ética, termo nebuloso, diz Deligny, que ele nunca usou antes de ler Wittgenstein. A "ética é o impulso que nos leva a dar cabeçada contra os limites da linguagem. É exatamente o trabalho do tomador de imagens. Seu trabalho essencial é estar impregnado da ideia de que se trata de ultrapassar os limites da linguagem, e não ficar escravizado por não sei qual sistema simbólico. É preciso atravessá-lo. Isso é a ética."(DELIGNY, 2007, p. 1675). Portanto, ir além ou aquém da linguagem, eis a aposta, eis o desafio, eis o impulso. Ou simplesmente reconhecer isto: "A imagem é a imagem, a linguagem é a linguagem. A imagem não se torna linguagem, e o inverso tampouco. (...) O agir não se torna fazer." Fazemos uma sopa, lavamos louça, fazemos pão.. Um autista, ainda que participe a seu modo desses afazeres, "não faz nada. Ele age." Agir (atividade sem objetivo) contra fazer (atividade com objetivo), imagem contra linguagem, inato contra civilizado, inquerer contra intenção, etologia contra fenomenologia. Se o estatuto dessas imagens ainda permanece turvo, é porque estamos por demais enredados numa infinidade de imagens (Deleuze as chamaria de clichês) que as recobrem. Talvez o que melhor o explicite é Deligny contando como os autistas por vezes ficam diante dos adultos como espectadores de cinema ou de televisão, assistindo a uma novela tediosa que não termina nunca. De repente, levantam e vão ver a água correndo. É quando seu olhar desperta, extasiado.

Chévrier tem razão. Para Deligny, a imagem não é algo que está lá, à nossa espera - bastaria entrar no cinema para encontrá-la. Ela pode ou não aparecer, pode revelar-se ou não ao longo de um filme. Ela não está na tela, mas "entre" o filme e o espectador... Ao mesmo tempo, num outro sentido ela sempre está aí, como traço permanente da espécie, infralinguística, memória de espécie. Talvez o instinto seja justamente o conjunto de imagens infraculturais que perpetuam a espécie. Em outras palavras: o cinema permanente da vida libera imagens que, embora permanentes como um fundo são descontínuas no seu aparecer. Onde aparecem elas? No gesto dissociado da fala, no mínimo 
gesto que salta da rotina (donde o título do filme de Deligny: Le moindre geste). O inadvertido que irrompe é indissociável do costumeiro, da repetição. Eis como o define Chévrier:

Para Deligny, o autismo foi um tipo de prodígio da existência liberada da reversibilidade do olhar. Janmari (o garoto autista que ele adotou) foi a encarnação da verdadeira imagem. A verdadeira imagem, que aparece, que não representa nada nem ninguém, tampouco tem necessidade de ser vista. Ela não precisa ser lida, decifrada, interpretada. Ela tem uma presença física, material, ela existe, num lugar dado, mas não tem conteúdo a revelar (...) A verdadeira imagem está liberada da marca do olhar. Ela escapa ao olho. Ela não está mais na (reta) linha do olhar, pois ela participa do curso das coisas, líquido ou aéreo. Ela levanta vôo! A imagem não pode satisfazer o olhar (...) Mas à avidez de ver, ao olho voraz pode responder, num outro plano, o êxtase (o levantar vôo) da imagem." (DELIGNY, 2007, p. 1779)

O refúgio de Deligny nas Cevenas terá sido uma tentativa de "destituir a fala", lembra Chévrier, num eremitismo talvez compensado pela sua escrita incessante. Pode-se dizer que Deligny se deixou possuir por Janmari, assim como outros fizeram voto de silêncio. Tudo isso para contrapor-se à ideologia da época, aos discursos repletos de palavras de ordem, à mobilização militar que se esconde na linguagem, nas instituições que ela cria, no partidarismo finalista e voluntarista que os autistas põem em xeque. Deligny "sonha em liberar a imagem da previsão verbal. Ele sonha com uma imagem encarnada que seria o traço vivo de uma existência nua", diz Chévrier. E com isso, ressoa remotamente talvez com a crítica contra o fetichismo da mercadoria, que faz da vida uma mercadoria intercambiável.

Chegados a esse ponto, é de perguntar-se a que ponto essa perspectiva, experiência, prática, na sua dimensão arcaica, pode dizer-nos algo, hoje, aqui, agora, sobre o estatuto da imagem em contextos singulares.

Tomemos os Yanomami, sobretudo através da prática do xamanismo tal como o descreve o antropólogo Bruce Albert, a partir de sua convivência com o xamã Davi Kopenawa. Em conversa ocorrida na aldeia Watoriki entre Laymert Garcia dos Santos, Bruce Albert e David Lapoujade, Stella Senra relata: 
As informações sobre o xamanismo Yanomami, oferecidas por Bruce Albert, chamam a atenção para o fato de que a particularidade desse povo, dentre os grupos indígenas da Amazônia, diz respeito, entre outros fatores, justamente à imagem. Enquanto aqueles (outros povos) têm uma produção plástica de objetos, máscaras (...), os Yanomami têm pouca produção dessa ordem, distinguindo-se por uma prática xamânica fundada na imagem -, mas numa imagem peculiar, que não depende de um suporte." Bruce Albert trata de precisar o sentido de Urupë, imagem vital: Tais imagens "são o corpo imediatamente. Mais propriamente, elas são coisa e passagem no corpo. (SENRA, 2011, p. 55)

O antropólogo, ao recusar a categoria do simbólico que sobredeterminaria o que é um estado do corpo, diz, a respeito do ritual xamânico:

o que escapa são esses momentos dos devires animais, são puramente onomatopeicos, movimentos corporais. Portanto, é um pouco a sobra da tentativa de domesticação pelo simbólico de todo esse magma induzido no cérebro, o que escapa a esse controle, que se torna, de tempos em tempos, um pouco paroxístico, que sai do simbólico e é puramente intensivo (...) O único momento em que elas (as imagens) existem é quando tomam corpo, tomam os corpos (...) tomada de corpo, na qual o simbólico sai de cena, e não fica senão o onomatopeico, o efeito corporal (...) O momento da tomada de corpo é fora da linguagem, além ou aquém da linguagem, não sei, mas é justamente o momento em que se vê o que não se vê (SENRA, 2011, p. 75).

Estamos às bordas de um Deligny, ainda que o contexto e até mesmo a problemática sejam inteiramente outras. Para completar, poderíamos utilizar as palavras de Viveiros de Castro na sua bela e complexa definição de espírito:

Um espírito, na Amazônia indígena, é menos assim uma coisa que uma imagem, menos uma espécie que uma experiência, menos um termo que uma relação, menos um objeto que um evento, menos uma figura representativa transcendente que um signo do fundo universal imanente - o fundo que vem à tona no xamanismo, no sonho e na alucinação, quando o humano e o não-humano, o visível e o invisível trocam de lugar (...) os conceitos amazônicos que traduzimos por "espírito" não designam, a rigor, entidades taxonômicas, e sim nomes de relações, experiências, movimentos e eventos, etc. (VIVEIROS DE CASTRO, 2020).

Como negar que estamos num domínio em que nossas categorias fazem água? Em que a própria ideia de ima- 
gem se vê "vivificada", referida a um plano vital, intensivo, no limite do corpóreo?

Laymert Garcia dos Santos, por sua vez, assim relata um episódio vivido com os xamãs, na preparação de sua Ópera transcultural "Amazônia":

Foram cinco dias muito intensos, com longas conversas com os pajés, captura de imagens e de sons dos rituais e da floresta, e sessões diárias de xamanismo, que duravam seis-oito horas ou mais. Certo dia, quando estávamos em pleno workshop, experienciamos um momento incrível no qual tivemos um insight que nos fez vislumbrar a complexidade da produção de imagens e de sons do xamanismo yanomami, de certo modo o "dispositivo tecnológico" singular e especialíssimo que essa cultura desenvolveu para acessar as potências da dimensão virtual da realidade.

Como de hábito, os xamãs faziam seu ritual, inalando yãkohana, cantando, dançando, falando... Subitamente, Levi Hewakalaxima (o pajé de voz e presença poderosas, cuja performance impressionara a todos na apresentação em Munique, em maio de 2008), dirigiu-se ao antropólogo Bruce Albert, apontou para nós, pôs a mão no próprio peito e disse, em yanomami: "Diga a eles que estou baixando em meu peito a imagem do canto-palavras do pássaro oropendola. " E de imediato "sintonizou" novamente o ritual, voltando a cantar e a dançar.

Fiquei assombrado. Pois pareceu-me que, durante essa espécie de download de um arquivo audiovisual, o corpo de Levi funcionava ao mesmo tempo como hardware e como software processando um programa que estava sendo rodado pela mente do xamã como som-canto do xapiripë tornando-se uma imagem que será "lida" como uma espécie de partitura pelo intérprete. De acordo com as palavras de Bruce Albert, "os sons-cantos do xapiripë vêm primeiro: as imagens mentais induzidas pela yãkohana tomam forma a partir de alucinações sonoras; o que significa um devir imagem do som. (GARCIA DOS SANTOS, 2013, p. 57).

Para completar esse circuito paralelo, evoquemos ainda a poesia de Lautréamont tal como lida por Laymert Garcia dos Santos. Segundo ele, o foco do poeta era menos a natureza da poesia do que sua fonte. De onde provêm as imagens (nesse caso, imagens poéticas)? E a resposta do autor é categórica: do corpo, da energia biopsíquica, da afecção, do movimento, em suma, do élan vital, para se expressar como Bergson. Deleuze daria a esse plano o nome de campo transcendental assubjeti- 
vo. É dali que jorram as imagens e as metamorfoses. Eis o que diz Laymert:

O poeta vai se tornando um selvagem. A procura da gênese da imagem evocada nas palavras transforma-se numa caçada frenética. (...) A visão de que a imagem não se origina na lei provoca então uma primeira metamorfose: na estrofe seguinte, Lautréamont-Maldoror sente-se um cadáver, é um homem-planta; mas a metamorfose post-mortem é limitada, e o processo precisa continuar. Lautréamont-Maldoror se posta diante do espelho, interroga a imagem nele refletida e vê que ela foi escalpelada: não passa de um fantasma, da fraca condensação de uma névoa. Como então se reconhecer na imagem? Melhor é quebrar o espelho ou atravessá-lo - pois, se o reflexo é ilusão de identidade, ainda não será aqui que se encontrará a origem da imagem das palavras." (GARCIA DOS SANTOS, 2019, p. 24)

Quão vizinhos estamos do tema caro a Deligny: como apagar a tinta preta que garante o reflexo especular? Não é o que ocorreria entre os autistas? E se agregamos ainda essa frase de Laymert: "Através de uma audaciosa comparação de sua literatura com o vôo dos bandos de estorninhos, o poeta enuncia que ambos obedecem à voz do instinto." (GARCIA DOS SANTOS, 2019, p. 25). Como os gansos de Deligny. Sim, trata-se aqui da imagem poética, portanto de linguagem, da relação entre energia e linguagem, conforme o precisa Laymert. Se uma coisa é a linguagem, outra a imagem, segundo Deligny, como ficamos? Deligny ele mesmo faz pontes, mas esburacadas: a vacância de linguagem e a escrita de Beckett...

Já podemos retornar, para finalizar, à questão do cinema. Deligny cita Malraux: "O modo de ligar o homem ao mundo por um outro meio que não a linguagem". Eis precisamente o que é o cinema para Deligny. Perguntamo-nos se não é similiar ao que diz Deleuze em seus livros sobre cinema, quando lembra que rompeu-se o elo entre o homem e o mundo. Não acreditamos mais no mundo: não na sua existência, mas em suas possibilidades. Trata-se de voltar a acreditar no mundo, isto é, em suas possibilidades. Seria a função do cinema. Ora, quando Deligny fala de um "povo de imagens" que habita como que o fundo da espécie humana, e que caberia como que "liberar", não se trata de um verbo gratuito. Pois para ele, a imagem e a revolução são o mesmo. Não cabe "querer-fazê"-la, 
mas praticar a escapada.. Eisenstein ou Stalin "queriam fazer", queriam construir a Catedral da Revolução.. Mas Deligny fala de uma urgência outra, a do escape. Maneira de dizer que a imagem ou a revolução não são fruto da vontade consciente, da deliberação: "a imagem assim como a revolução não se fazem: elas acontecem a partir de circunstâncias completamente independentes da vontade e da ação." (DELIGNY, 2007, p. 1737) Para que tal involuntário advenha, para sustentar o inquerer, é preciso proceder por muitos desvios, pois cabe driblar o dado, para inadvertidamente topar com. Ou seja, há toda uma malícia do aproximar-se de, todo um respeito a sustentar a espera, toda uma arte de voltear, de perder-se, de perder o $\mathrm{Si}$ - na contramão do olhar policialesco ou partidarista que vai direto ao ponto, que delata o crime ou decide o trajeto. Apenas nessa perda pode-se encontrar esse elemento de onde a imagem pode ser colhida ${ }^{1}$, que no entanto é já movimento, kinema em grego.

\section{Referências}

DELIGNY, Fernand. Oeuvres. Paris : Ed. Arachnéen, 2007.

SENRA, Stella. Conversações em Watoriki: Das passagens de imagem às imagens de passagens: captando o audiovisual do xamanismo. Cadernos de Subjetividade, ano 8, n. 13, out. 2011, pp. 55-77.

VIVEIROS DE CASTRO, Eduardo. A floresta de cristal e outros ensaios de antropologia. São Paulo: n-1 edições, 2020 (no prelo).

GARCIA DOS SANTOS, Laymert. Amazonia transcultural, xamanismo e tecnociência na ópera. São Paulo: n-1 edições, 2013.

GARCIA DOS SANTOS, Laymert. Às voltas com Lautréamont. São Paulo: n-1 edições, 2019.

$1 \quad$ Idem, p. 1739. Inspiro-me aqui do texto de Sandra Alvarez de Toledo, editora da obra do autor. 